\title{
A comparative study to determine vitamin $D$ status in type 2 diabetes and normal subjects in south India
}

\author{
R. Anil Kumar ${ }^{1}$, R. Lalitha ${ }^{2}$, Surekha B. Shetty ${ }^{3}$ \\ ${ }^{1}$ Dr. R. Anil Kumar, Assistant Professor, ${ }^{2}$ Dr. R. Lalitha, Assistant Professor, ${ }^{3}$ Dr. Surekha B. Shetty, Assistant \\ Professor. All authors are affiliated to Karnataka Institute of Endocrinology and Research Bangalore, Karnataka, \\ India.
}

Address for Correspondence: Dr. R. Anil Kumar, E-mail: r.anil_kumar@yahoo.co.in

\begin{abstract}
Background: Vitamin D deficiency is common in general population in India in spite of adequate sunlight. We have decided to compare the prevalence of vitamin D deficiency in type 2 diabetes and normal individuals. Methods: 370 type 2 diabetes individuals attending Karnataka Institute of endocrinology and research outpatient department and 100 normal individuals were studied. Fasting plasma glucose, post prandial plasma glucose, lipid profile, vitamin D levels, BMI, waist circumference and BP of these subjects were measured. Results: Out of 370 type 2 diabetes subjects $67.3 \%$ were males and age group ranging from 21 to 80 years. Duration of diabetes vary from 0 to 20 years. Vitamin D deficiency was present in $83 \%$, insufficiency in $13.8 \%$ and only $3.2 \%$ had normal vitamin D levels in type 2 diabetes. Vitamin D deficiency was common in individuals $>50$ years, males, BMI 25-30. Family history of diabetes was present in $60 \%$. Hypertension was present in $47.6 \%$. Total cholesterol, LDL, Triglycerides were lower and HDL levels were higher in type 2 diabetes individuals with vitamin D more than 20 nanograms per ml. In 100 normal individuals taken as controls $62 \%$ were males, age group ranging from 21 to 80 years. Vitamin D deficiency was present in $82 \%$ and insufficiency in $12 \%$ and $6 \%$ had normal vitamin D levels. Conclusions: Vitamin D deficiency was present in $83 \%$ of type 2 diabetes individuals and $82 \%$ of normal individuals. So both type 2 diabetes and normal controls from south India are equally deficient in vitamin D. Total cholesterol, LDL, Triglycerides were lower and HDL levels were higher in type 2 diabetes individuals with vitamin D more than 20 nanograms per $\mathrm{ml}$.
\end{abstract}

Key words:Vitamin D, Type 2 diabetes,insulin sensitivity

\section{Introduction}

Vitamin D is a secosteroid which is converted into its active form via $1 \alpha$-hydroxylase enzyme. Though kidney is the classical site for $1 \alpha$ hydroxylase activity, it is also expressed in other tissues such as endothelial and vascular smooth muscle cells. [1]. Besides, vitamin D receptor (VDR) is present in more than 30 different tissues including pancreas, myocardium, lymphocytes, etc. The widespread distribution of VDR signifies important role of vitamin D in humans [2].

Prevalence of Vitamin D deficiency- Currently the prevalence of type $2 \mathrm{DM}$ is high in urban as well as rural India [3,4] and by 2030, Asian Indian

Manuscript received: $28^{\text {th }}$ September 2017

Reviewed: $8^{\text {th }}$ October 2017

Author Corrected: $17^{\text {th }}$ October 2017

Accepted for Publication: $23^{\text {rd }}$ October 2017 would bear the maximum burden of the disease in the world. [5]. Glycaemic control tends to worsen in winter months and is believed to be because of concomitant fall in $25(\mathrm{OH}) \mathrm{D}$ in this season. [6,7].

Pittaset al has systematically reviewed world literature related to [8].

1. association between VDD and prevalence/ incidence of type $2 \mathrm{DM}$ in different population, and

2. randomized trials assessing role of vitamin D supplementation on glucose metabolism

The results of the above review, the evidence from the observational studies suggests an association between low vitamin $\mathrm{D}$ status and calcium intake (including low dairy intake) and risk of type 2DM 
or metabolic syndrome. However, definite conclusions from these studies are limited for a variety of reasons. In cross-sectional or casecontrol studies, vitamin D or calcium status was measured in patients with glucose intolerance or established diabetes, therefore these measures may not reflect vitamin D or calcium status prior to diagnosis and, as a result, the causative nature of the observed associations cannot be established. There is considerable variability in studied cohorts (normal glucose tolerance vs. diabetes [newly diagnosed vs. established], ethnicity, latitude etc). In most studies, there is lack of adjustment for important confounders, such as adiposity, physical activity, and importantly, vitamin D or calcium status.

Skin complexion, poor sun exposure, vegetarian food habits and lack of vitamin D food fortification program in the country explain the high prevalence of VDD in India despite its sunny climate.

Vitamin D and Type 2 DM: While vitamin D is critical for calcium homeostasis, current studies also highlight role of vitamin D deficiency (VDD) in diseases other than the metabolic bone disorders. The potential mechanisms of beneficial effect of vitamin $\mathrm{D}$ in type $2 \mathrm{DM}$ include

(i) Improved $\beta$-cell function via direct effect of vitamin $\mathrm{D}$ or by increase in the intracellular ionized calcium which therefore would result in enhanced insulin release.

(ii) Increased insulin sensitivity related to expression of insulin receptor or via calcium dependent pathways in target cells leading to increase in the glucose utilization, and

(iii) Inhibition of $\beta$-cells apoptosis due to VDR transcription factor mediated inhibition of cytotoxic cytogene expression.

Research methods and statistical analysis- Study design and participants-370 South Indian type 2 diabetic individuals attending Karnataka Institute of endocrinology outpatient department were assessed for fasting and post-prandial plasma glucose, lipid profile, vitamin D levels, BMI, waist circumference and hypertension. 100 South Indian normal individuals were used as controls. Informed consent was obtained from all the participants. Inclusion criteria- All type 2 diabetes patients with age more than 20 and less than 80 years, duration of diabetes new to 20 years were included in the study.

Sample collection-venous blood sample collected under aseptic precautions and vitamin D was estimated by chemiluminescence.

Exclusion criteria-Patients taking vitamin D supplementation or having hepatic, renal or metabolic bone disorders (including parathyroid related problems) were excluded from the study.

Also, those patients with use of glucocorticoids or anti-seizure medications in the previous 6 months; or those patients having history of malabsorption syndromes such as celiac disease or active malignancy or with active infection were excluded from the study. Patients were also excluded if they had any severe medical illness, such as sepsis, severe infection, malignancy, liver cirrhosis, heart failure, or renal failure.

Statistical methods-Descriptive statistical analysis was carried out in the present study. Results on continuous measurements were presented on Mean \pm SD (Min-Max) and results on categorical measurements were presented in Number (\%). Significance was assessed at 5\% level of significance. Analysis of variance (ANOVA) was used to find the significance of study parameters between three or more groups of patients. Chisquare/ Fisher Exact test was used to find the significance of study parameters on categorical scale between two or more groups. The Statistical software namely SAS 9.1.3, SPSS 10.0 was used for the analysis of the data.

\section{Results}

370 type 2 diabetes subjects were studied. 673\% were males and age group ranging from 21 to 80 years. Duration of diabetes vary from 0 to 20 years. Vitamin D deficiency was present in $83 \%$, insufficiency in $13.8 \%$ and only $32 \%$ had normal vitamin D levels.In 100 South Indian normal individuals taken as controls $62 \%$ were males, age group ranging from 21 to 80 years. Vitamin D deficiency was present in $82 \%$ and insufficiency in $12 \%$ and $6 \%$ had normal vitamin D levels.(Table1). Family history of diabetes was present in $60 \%$. Hypertension was present in $47.6 \%$. 
Table- 1: Prevalence of Vitamin D deficiency in type 2 diabetes and normal subjects.

\begin{tabular}{|c|c|c|c|c|}
\hline Vitamin D $(\mathbf{n g} / \mathbf{m l})$ & $\begin{array}{c}\text { Number of type 2 } \\
\text { diabetes subjects }\end{array}$ & Percentage & $\begin{array}{c}\text { Number of } \\
\text { normal subjects }\end{array}$ & Percentage \\
\hline Deficient $(<20 \mathrm{ng} / \mathrm{ml})$ & 307 & 83 & 82 & 82 \\
\hline Insufficiency $(>20-30 \mathrm{ng} / \mathrm{ml})$ & 51 & 13.8 & 12 & 6 \\
\hline Normal $(>30 \mathrm{ng} / \mathrm{ml})$ & 12 & 3.2 & 6 & $\mathbf{1 0 0}$ \\
\hline Total & $\mathbf{3 7 0}$ & $\mathbf{1 0 0 . 0}$ & $\mathbf{1 0 0}$ & 6 \\
\hline
\end{tabular}

Vitamin D deficiency was common in individuals $>50$ years, males, BMI 25-30, duration of diabetes ranging from less than one year to more than 10 years. (Table2)

Table- 2: Correlation of Clinical variables with levels of Vitamin D levels in type 2 diabetes individuals.

\begin{tabular}{|c|c|c|c|c|c|}
\hline \multirow[t]{2}{*}{ Clinical variables } & \multicolumn{4}{|c|}{ Levels of Vitamin D } & \multirow[t]{2}{*}{ P value } \\
\hline & $\begin{array}{c}\text { Deficient }(<10 \\
\text { ng/ml }) \\
(n=166)\end{array}$ & $\begin{array}{c}\text { Insufficiency (10- } \\
20 \mathrm{ng} / \mathrm{ml}) \\
(\mathrm{n}=141)\end{array}$ & $\begin{array}{c}\text { Insufficiency } \\
(21-30 \mathrm{ng} / \mathrm{ml}) \\
\quad(\mathrm{n}=51)\end{array}$ & $\begin{array}{c}\text { Normal (>30 } \\
\text { ng/ml) } \\
(n=12)\end{array}$ & \\
\hline \multicolumn{6}{|l|}{ Age in years } \\
\hline - $\quad<50$ years & $57(34.3 \%)$ & $50(35.5 \%)$ & $21(41.2 \%)$ & $1(8.3 \%)$ & \multirow[t]{2}{*}{0.199} \\
\hline - $\quad>50$ years & $109(65.7 \%)$ & $91(64.5 \%)$ & $30(58.8 \%)$ & $11(91.7 \%)$ & \\
\hline \multicolumn{6}{|l|}{ Gender } \\
\hline - Male & $105(63.3 \%)$ & $98(69.5 \%)$ & $38(74.5 \%)$ & $8(66.7 \%)$ & \multirow[t]{2}{*}{0.431} \\
\hline - $\quad$ Female & $61(36.7 \%)$ & $43(30.5 \%)$ & $13(25.5 \%)$ & $4(33.3 \%)$ & \\
\hline \multicolumn{6}{|l|}{ BMI $\left(\mathrm{kg} / \mathrm{m}^{2}\right)$} \\
\hline - $\quad<18.5$ & $1(0.6 \%)$ & $0(0 \%)$ & $1(2 \%)$ & $0(0 \%)$ & \multirow[t]{4}{*}{0.232} \\
\hline - $\quad 18.5-25.0$ & $61(36.7 \%)$ & $56(39.7 \%)$ & $26(51 \%)$ & $3(25 \%)$ & \\
\hline - $\quad 25.0-30.0$ & $73(44 \%)$ & $54(38.3 \%)$ & $18(35.3 \%)$ & $8(66.7 \%)$ & \\
\hline - $\quad>30.0$ & $31(18.7 \%)$ & $31(22 \%)$ & $6(11.8 \%)$ & $1(8.3 \%)$ & \\
\hline \multicolumn{6}{|l|}{ Duration of DM } \\
\hline - New cases & $8(4.8 \%)$ & $8(5.7 \%)$ & $1(2 \%)$ & $0(0 \%)$ & \multirow[t]{6}{*}{$<0.001 * *$} \\
\hline - $\quad<1$ years & $8(4.8 \%)$ & $12(8.5 \%)$ & $3(5.9 \%)$ & $0(0 \%)$ & \\
\hline - $1-2$ years & $19(11.4 \%)$ & $28(19.9 \%)$ & $7(13.7 \%)$ & $1(8.3 \%)$ & \\
\hline - $2-5$ years & $31(18.7 \%)$ & $24(17 \%)$ & $12(23.5 \%)$ & $1(8.3 \%)$ & \\
\hline - 5-10 years & $48(28.9 \%)$ & $33(23.4 \%)$ & $12(23.5 \%)$ & $3(25 \%)$ & \\
\hline - $\quad>10$ & $52(31.3 \%)$ & $36(25.5 \%)$ & $16(31.4 \%)$ & $7(58.3 \%)$ & \\
\hline \multicolumn{6}{|l|}{ Hypertension } \\
\hline - $\quad$ No & $86(51.8 \%)$ & $67(47.5 \%)$ & $20(39.2 \%)$ & $3(25 \%)$ & \multirow[t]{2}{*}{0.167} \\
\hline - Yes & $80(48.2 \%)$ & $74(52.5 \%)$ & $31(60.8 \%)$ & $9(75 \%)$ & \\
\hline
\end{tabular}

HDL levels were higher in those with vitamin D levels more than 20 and $30 \mathrm{mg} / \mathrm{dl}$ when compared to patients with vitamin D levels less than $20 \mathrm{mg} / \mathrm{dl}$. We can assume that correction of vitamin D deficiency may help in increasing HDL levels which reduces atherosclerosis. But this has to be further confirmedby larger studies. (Table 3) 
Table-3: Comparison of T.C, TG HDL, LDL \& VLDL with Vitamin D in four groups studied.

\begin{tabular}{|c|c|c|c|c|c|}
\hline $\begin{array}{c}\text { Vitamin D } \\
(\mathbf{n g} / \mathbf{m l})\end{array}$ & $\begin{array}{c}\text { Deficient }(<\mathbf{1 0} \\
\mathbf{n g} / \mathbf{m l})\end{array}$ & $\begin{array}{c}\text { Insufficiency } \\
\mathbf{( 1 0 - 2 0} \mathbf{~ n g} / \mathbf{m l})\end{array}$ & $\begin{array}{c}\text { Insufficiency } \\
\mathbf{( 2 1 - 3 0} \mathbf{~ n g} / \mathbf{m l})\end{array}$ & $\begin{array}{c}\text { Normal }(>30 \\
\mathbf{n g} / \mathbf{m l})\end{array}$ & P value \\
\hline $\begin{array}{c}\text { Total cholesterol } \\
(\mathbf{m g} / \mathbf{d l})\end{array}$ & $173.12 \pm 42.06$ & $172.61 \pm 45.41$ & $162.96 \pm 33.81$ & $161.08 \pm 39.14$ & 0.375 \\
\hline TG & $158.22 \pm 115.68$ & $161.33 \pm 135.04$ & $140.98 \pm 59.11$ & $119.58 \pm 54.72$ & 0.500 \\
\hline HDL & $39.87 \pm 9.79$ & $38.58 \pm 9.43$ & $40.56 \pm 8.50$ & $43.67 \pm 8.42$ & 0.211 \\
\hline LDL & $101.50 \pm 34.66$ & $102.06 \pm 33.61$ & $93.07 \pm 31.91$ & $93.83 \pm 32.71$ & 0.344 \\
\hline VLDL & $31.20 \pm 23.43$ & $30.43 \pm 22.99$ & $28.14 \pm 12.04$ & $23.67 \pm 11.19$ & 0.593 \\
\hline
\end{tabular}

\section{Discussion}

Type 2 Diabetes Mellitus (T2DM) is the commonly seen endocrine disorder characterized by hyperglycemia. The International Diabetes Federation (IDF 2015) estimates around 69.2 million diabetic individuals in India with a global estimate of 415 million diabetics. There are several factors that seem to play a role in its development including genetic, lifestyle, environmental and nutritional conditions. Amongst nutritional factors, vitamin D is likely to have an important role either in glycemic control or in attenuating diabetic complications. The probable mechanisms indicating the role of vitamin D in glucose homeostasis is likely to be through beta cell dysfunction and insulin resistance in cases with vitamin D deficiency.

Vitamin D deficiency is now regarded as pandemic in all age groups in humans. The cross-sectional study involving largest cohort of non diabetic Americans $(\mathrm{n}=6288)$ reported an inverse relationship between serum $25(\mathrm{OH})$ D concentration and fasting or post glucose load values. $[8,9]$. In nine of 13 case-control studies reviewed by the authors, patients with type 2 diabetes showed a lower mean $25(\mathrm{OH})$ D concentrations than the non diabetic controls. Association between vitamin D intake and incidence of type $2 \mathrm{DM}$ was examined in Women's Health Study. [8,10]. Subjects with daily vitamin D intake $>511$ IU had lower risk of incidence of DM when compared to a cohort with daily vitamin D intake of $<159$ IU per day $(27 \%$ vs. $56 \%)$. Pittas et alalso examined association between combined vitamin $\mathrm{D}$ and calcium intake and incidence of type 2 DM among 83,806 women in Nurses Health Study. After adjusting for age, BMI, and non dietary covariates, a significant inverse association was observed between vitamin $\mathrm{D}$ intake and calcium intake on one hand and risk of type $2 \mathrm{DM}$ on the other [11]. There is a paucity of interventional trials assessing effect of vitamin D supplementation on glycaemic control over long term period. Pittas et al studied 92 diabetic subjects and reported decrease in fasting plasma glucose after $3 \mathrm{yr}$ in group receiving daily supplementation of 700 IU of vitamin D and $500 \mathrm{mg}$ of calcium citrate. [12].

Davidet al has shown that $63.5 \%$ of type 2 diabetes individuals compared to $36 \%$ of type 1 diabetes were deficient in vitamin D. [13]. Goswamiet alof AIIMS in 2000 measured vitamin D levels in apparently healthy subjects in Delhi and showed that significant vitamin D deficiency was present in $90 \%$ of them [14]. Rajesh et al in their pilot study showed that $967 \%$ of Asian Indian patients with fragility hip fracture were deficient in vitamin D [15]. Harinarayananet alreported vitamin D deficiency in $62 \%$ and $72 \%$ in urban males and females, $44 \%$ and $77 \%$ rural males and females in south India[16]. Marwaha et alreported prevalence of vitamin D deficiency in $912 \%$ of healthy Indians aged above 50 years [17].

There are no studies regarding prevalence of vitamin $\mathrm{D}$ deficiency in type 2 diabetics in south India. Our study shows the prevalence of vitamin D deficiency in $83 \%$ and insufficiency in $138 \%$ of south Indian type 2 diabetes individuals. South Indian normal individuals taken as controls had vitamin $\mathrm{D}$ deficiency in $82 \%$ and insufficiency in $12 \%$. The present study has also shown a higher incidence of vitamin D deficiency in overall recruited subjects indicating that both T2DM (83\%) subjects and non-diabetic control subjects $(82.0 \%)$ were equally deficient. This is in accordance with other studies demonstrating low serum vitamin D levels in $70 \%$ to $100 \%$ populations across India. 
The high percentage of VDD in this study was explained by decreased sunshine exposure, limited outdoor activities, dark complexion and decreased awareness about fortification with vitamin D. Although sunshine exposure is good in India, it is limited to only few months, and fortification of food with vitamin D is not routine in the country.

Whether vitamin D status in patients with diabetes has a role in the pathogenesis of diabetes mellitus in patients needs to be elucidated in future studies. It has been argued by Lo et al. that to meet an adequate requirement of vitamin $\mathrm{D}$, people in India require sun exposure almost double than Caucasians due to increased skin pigmentation. $[18,19]$. Life style factors like in-door working or working in close environment with minimum sun exposure is also likely for high prevalence of vitamin D deficiency in our population. Normal office hours in India are usually from 10 am to 6 pm while maximum sun exposure and absorption is between 11 am to $2 \mathrm{pm}$ with an UV index of 7-9 required for conversion of 7-dehydrocholesterol to pre-vitamin $D_{3}[20]$. But this seems to be unrealistic as being a tropical country summers in India are very hot, forcing most of its people to stay indoor during this time. This results in low exposure to the sunlight contributing for very low vitamin $\mathrm{D}$ status in our population.

\section{Conclusions}

Vitamin D deficiency was present in $83 \%$ of type 2 diabetes individuals and $82 \%$ of normal individuals. So both south Indian type 2 and normal persons are equally deficient in vitamin D. HDL levels were higher in type 2 diabetes individuals with vitamin D more than 20 nanograms per ml.

We can assume that correction of vitamin D deficiency may help in increasing HDL levels which reduces atherosclerosis but this has to be further validated by larger studies. Correction of vitamin $\mathrm{D}$ deficiency in type 2 diabetes may help in improving glycemic control. This has to be further validated by further studies in India.

Acknowledgement: Dr. K. P. Suresh, Scientist (Biostatistics), National Institute of Animal Nutrition \& Physiology, Bangalore-560030.

Funding: Nil, Conflict of interest: None Permission of IRB: Yes

\section{References}

1. Zehnder D, Bland R, Williams MC, McNinch RW, Howie AJ, Stewart PM, Hewison M. Extrarenal expression of 25-hydroxyvitamin $\mathrm{d}(3)-1$ alpha- hydroxylase. J Clin Endocrinol Metab. 2001 Feb; 86 (2): 888-94.

2. Norman AW. Minireview: vitamin D receptor: new assignments for an already busy receptor. Endocrinology. 2006 Dec; 147(12): 5542-8. Epub 2006 Aug 31.

3. Ramachandran A, Snehalatha C, Kapur A, Vijay V, Mohan V, Das AK, Rao PV, Yajnik CS, Prasanna Kumar KM, Nair JD; Diabetes Epidemiology Study Group in India (DESI). Highprevalence of diabetes and impaired glucose tolerance in India: National Urban Diabetes Survey. Diabetologia. 2001Sep; 44(9):1094-101.

4. Chow CK, Raju PK, Raju R, Reddy KS, Cardona M, Celermajer DS, Neal BC. The prevalence and management of diabetes in rural India. Diabetes Care. 2006 Jul;29(7):1717-8.

5. Wild S, Roglic G, Green A, Sicree R, King H. Globalprevalence of diabetes: estimates for the year 2000 and projections for 2030. Diabetes Care.2004 May; 27(5):1047-53.

6. Ishii H, Suzuki H, Baba T, Nakamura K, Watanabe T. Seasonal variation of glycemic control in type 2 diabetic patients. Diabetes care. 2001 Aug 1;24(8):1503-.

7. Campbell IT, Jarrett RJ, Keen H. Diurnal and seasonal variation in oral glucose tolerance: studies in the Antarctic. Diabetologia. 1975 Apr;11(2): 139-45.

8. Pittas AG, Lau J, Hu FB, Dawson-Hughes B. Theroleofvitamin $\mathrm{D}$ and calcium in type 2 diabetes. A systematic review and meta-analysis. J Clin Endocrinol Metab. 2007 Jun; 92(6): 2017-29. Epub 2007 Mar 27.

9. Scragg R, Sowers M, Bell C; Third National Health and Nutrition Examination Survey. Serum 25-hydroxy vitamin $\mathrm{D}$, diabetes, and ethnicity in the Third National Health and Nutrition Examination Survey. Diabetes Care. 2004 Dec; 27 (12): 2813-8. 
10. Liu S, Song Y, Ford ES, Manson JE, Buring JE, Ridker PM. Dietary calcium, vitamin D, and the prevalence of metabolicsyndrome in middle-aged and older U.S. women. Diabetes Care.2005Dec;28 (12): 2926-32.

11. Pittas AG, Dawson-Hughes B, Li T, Van Dam RM, Willett WC, Manson JE, Hu FB. Vitamin D and calcium intake in relation to type 2 diabetes in women. Diabetes Care. 2006 Mar; 29(3):650-6.

12. Pittas AG, Harris SS, Stark PC, DawsonHughes B. The effects of calcium and vitamin Dsupplementation on blood glucose and markers of inflammation in nondiabeticadults. Diabetes Care. 2007 Apr;30(4):980-6. Epub 2007 Feb 2.

13. Di Cesar DJ, Ploutz-Snyder R, Weinstock RS, Moses AM. Vitamin D deficiency is more common in type 2 than in type 1 diabetes. Diabetes Care. 2006 Jan;29(1):174.

14. Goswami R, Gupta N, Goswami D, Marwaha RK, Tandon N, Kochupillai N. Prevalence and significance of low 25-hydroxy vitamin Dconcentrations in healthy subjects in Delhi. Am J Clin Nutr. 2000Aug;72(2):472-5.

15. Khadgawat R, Brar KS, Gahlo M, Yadav CS, Malhotra R, Guptat N, Tandon N. Highprevalence of vitamin $\mathrm{D}$ deficiency in Asian-Indianpatients with fragilityhip fracture: a pilot study. J Assoc Physicians India. 2010 Sep;58:539-42.

16. Harinarayan CV, Ramalakshmi T, Prasad UV, Sudhakar D, Srinivasarao PV, Sarma KV, Kumar EG. High prevalence of low dietary calcium, high phytate consumption, and vitamin D deficiency in healthy south Indians. The American journal of clinical nutrition. 2007 Apr 1; 85 (4): 1062-7.

17. Marwaha RK, Tandon N, Garg MK, Kanwar R, Narang A, Sastry A, Saberwal A, Bandra K. Vitamin D status in healthy Indians aged 50 years and above. J Assoc Physicians India. 2011 Nov; 59: 706-9.

18. Lo CW, Paris PW, Holick MF. Indian and Pakistaniimmigrants have thesamecapacity as Caucasians to producevitamin $\mathrm{D}$ in response to ultravioletirradiation. Am J Clin Nutr.1986Nov; 44 (5): 683-5.

19. Lips P, van Schoor NM, de Jongh RT. Diet, sun, and lifestyle as determinants of vitamin D status. Ann N Y Acad Sci. 2014 May;1317:92-8. doi: 10.1111/nyas.12443. Epub 2014 May 9.

20. Harinarayan CV, Joshi SR. Vitamin D status in India--its implications and remedial measures. J Assoc Physicians India. 2009 Jan; 57:40-8.

\section{How to cite this article?}

R. Anil Kumar, R. Lalitha, Surekha B. Shetty. A comparative study to determine vitamin D status in type 2 diabetes and normal subjects in south India. Int J Med Res Rev 2017;5(10):888-893.doi:10.17511/ijmrr. 2017.i10.03 